\title{
Fatores de risco e proteção vivenciados por mães encarceradas ao longo da vida
}

\section{Risk and protective factors experienced by incarcerated mothers in life}

\section{Factores de riesgo y protección experimentados por madres presas durante su vida}

\author{
Gabriela Reyes Ormeno* \\ Universidade Federal do Paraná - UFPR, Paraná, Brasil
}

Paolla Magioni Santini**

Pontifícia Universidade Católica de Minas Gerais - PUC-MG, Minas Gerais, Brasil

Lúcia Cavalcanti de Albuquerque Williams***

Universidade Federal de São Carlos - UFSCar, São Paulo, Brasil

\begin{abstract}
RESUMO
Este estudo objetivou descrever o perfil de mães encarceradas, identificando-se os fatores de risco e proteção, vivenciados ao longo de suas vidas, através de entrevista semiestruturada em cadeias e penitenciárias do Estado de São Paulo com 152 mães encarceradas. Tal amostra apresentou um perfil de uma mãe jovem, solteira, com três filhos, afrodescendente, de baixa renda e escolaridade, e tendo cometido o crime de tráfico de drogas. Foram identificados os seguintes fatores de risco: a) na infância: exposição à violência conjugal entre os pais; maus-tratos, sendo a punição corporal a modalidade mais frequente; e a prisão de um familiar; b) na vida adulta: violência pelo parceiro íntimo; familiares encarcerados; uso abusivo de álcool, tabaco e drogas; e tentativas de suicídio. Apenas um fator de proteção na infância foi relatado: um cuidador que as valorizaram positivamente, fazendo com que se sentissem especiais.
\end{abstract}

Palavras-chave: risco, proteção, prisioneiros, mulheres, mães.

\begin{abstract}
This study aimed at describing the profile of incarcerated mothers and identifying risk and protective factors experienced throughout their lives. A semi-structured interview was conducted in prisons and penitentiaries of São Paulo State with 152 incarcerated mothers. Such sample showed an incarcerated mother's profile as young, Afro-Brazilian, single, with three children, with low-income and educational level, and committed drug trafficking. The following risk factors were identified: a) in childhood: exposure to domestic violence between parents; child maltreatment in which corporal punishment was the most common modality; and imprisonment of a family member; b) in adulthood: intimate partner violence; having
\end{abstract}


incarcerated relatives; abusive use of alcohol, tobacco and illicit drugs; and suicide attempts. Only one protective factor in childhood was reported: a caregiver who appreciated them positively, making them feels special.

Keywords: risk, protection, inmates, women, mothers.

\section{RESUMEN}

Este estudio tuvo como objetivo describir el perfil de madres encarceladas y identificar factores de riesgo y protección experimentados durante su vida. Una entrevista semiestructurada se llevó a cabo en las cárceles y prisiones de São Paulo con 152 madres encarceladas. Los resultados mostraran un perfil de madre joven, soltera, con tres hijos, de ascendencia africana, de bajos ingresos y educación, que han cometido delito de narcotráfico. Los siguientes factores de riesgo se han identificado: a) en la infancia: la exposición a la violencia doméstica entre los padres; maltrato, siendo el castigo corporal el tipo más común; y la detención de un miembro de la familia; b) en la edad adulta: la violencia por su pareja; familiares encarcelados; abuso de alcohol, tabaco e drogas; y los intentos de suicidio. Sólo un factor protector en la infancia se informó: un cuidador que valoran positivamente, haciendo que se sientan especiales.

Palabras-clave: riesgo, protección, prisioneros, mujeres, madres.

\section{I ntrodução}

Estudos apontam que a população carcerária brasileira tem tido um aumento expressivo: em dezembro de 2000 era de 232.755 presos, e em 2002 aumentou para 548.003 (Infopen, 2014). Tal contexto situa - Brasil na quarta posição dentre os países com maior número de encarcerados no mundo, atrás somente dos Estados Unidos, China e Rússia (International Centre for Prison Studies, 2013).

Especificamente sobre a população carcerária feminina brasileira, em 2000, a população era de 10.112 mulheres, e as últimas estatísticas publicadas revelaram um contingente de 33.793 (Infopen, 2014), dados que demonstram que essa população mais que triplicou em 14 anos. Tal escalonamento torna-se ainda mais preocupante ao se considerar os problemas apresentados pelos presídios, como a falta de vagas e de estrutura física adequada, o fracasso na recuperação e reinserção da população carcerária, práticas de castigo e humilhação e falta de políticas públicas às mulheres encarceradas (Diuana, Ventura, Simas, Larouzé \& Correa, 2016).

Em geral, o perfil sociodemográfico da mulher encarcerada no Brasil é descrito como sendo o de jovens, solteiras, com baixo nível de escolaridade, renda familiar precária e com filhos (Audi, Santiago, Andrade \& Francisco, 2016; Ormeno \& Stelko-Pereira, 2013). O fato de que a maioria das encarceradas é mãe estabelece a necessidade de atenção especial para a prevenção de uma futura geração carcerária, que seria de filhos de mães presas. Uma das maneiras para promover políticas públicas para tal prevenção seria a 
identificação de fatores de risco e proteção presentes ao longo da vida da mãe encarcerada.

Fatores de risco são compreendidos com os contextos que contribuem para o desenvolvimento de problemas de saúde, comportamentais ou emocionais nos indivíduos, e podem ser classificados nas seguintes categorias: a) Individuais: propensões biológicas ou genéticas a transtornos mentais; b) de relacionamento: exposição à violência doméstica; utilizar punição corporal como forma de disciplina; c) da comunidade: tolerância à violência; desigualdade social e de gênero na comunidade; falta de serviços de apoio para a família e carência de instituições que lidem com necessidades especializadas; altos índices de desemprego; pobreza; tráfico de drogas; d) da sociedade: falta de políticas sociais; econômicas; de saúde e de educação; presença de normas que glorificam a violência; rigidez de papel de gêneros; exposição à pornografia infantil; trabalho infantil; etc. (Maia \& Williams, 2005). No mesmo sentido, os fatores de proteção são conceituados como influências que diminuem as expectativas de consequências negativas ao desenvolvimento da pessoa. Podemos citar alguns exemplos de acordo com as seguintes áreas: a) Atributos do indivíduo: orientação social positiva; autonomia; autoestima; b) Características da família: coesão; afetividade; resolução de problemas sem o uso da violência; c) Fontes de apoio: relacionamento saudável entre pares; suporte cultural; acesso a atendimento médico; instituições religiosas; etc. (Maia \& Williams, 2005). Nos casos em que existem diversas situações de risco em um mesmo contexto, o acúmulo de tais fatores pode extenuar os fatores de proteção, deixando 0 indivíduo em uma situação de vulnerabilidade (Zavaschi, 2009).

Há escassez de estudos brasileiros que busquem identificar os fatores de risco e proteção à mulher encarcerada de forma direta, pois as pesquisas estão geralmente ligadas à saúde da mulher, ao crime cometido, ou a religiosidade dentro do ambiente prisional (Dell Agnolo, Belentani, Jardim, Carvalho, \& Pelloso, 2013; Ferreira, Silva, Noronha Neto, Falbo Neto, Chaves \& Bello, 2014; Quitete, Paulino, Hauck, Aguiar-Nemer \& Silva-Fonseca, 2012). Em um estudo com 287 mulheres encarceradas no Rio Grande do Sul (Canazaro \& Argimon, 2010), o perfil das participantes foi identificado como sendo a maioria solteira, jovem, tendo no mínimo dois filhos e tendo exercido atividades informais. Salientam-se como fatores de risco: baixa renda; baixa escolaridade; maus-tratos na infância (incluindo abuso sexual); fuga de casa; uso abusivo de álcool e drogas; exposição a parentes que faziam uso abusivo de álcool/drogas; parentes com problemas de saúde mental; e ideação suicida. Assim, as autoras apontam que tais mulheres sofreram de insuficiência material, educacional e afetiva (Canazaro \& Argimon, 2010). 
O estudo de Ferreira et al. (2014) investigou a prevalência e os fatores associados à violência sofrida antes ao encarceramento de 209 mulheres em situação de encarceramento por tráfico de drogas na Colônia Penal Feminina no Estado de Pernambuco. Os resultados mostraram que $47.3 \%$ usaram drogas ilícitas e $67.5 \%$ desenvolveram algum papel no tráfico de drogas; $44.1 \%$ relataram ter sofrido violência vinte e quatro meses antes do encarceramento (físicas $35.2 \%$, psicológicas $31.8 \%$ e sexuais $3.8 \%$ ), sendo o companheiro identificado como perpetrador mais frequente (44.1\%). Assim, evidencia-se que estas mulheres estão em situação de vulnerabilidade antes de ingressar no sistema prisional.

Outro estudo recente visando avaliar o perfil sociodemográfico e as condições de saúde de 1.013 encarceradas, numa penitenciária no interior de São Paulo, mostrou resultados similares aos encontrados no Rio Grande do Sul: $61.4 \%$ apresentou baixa escolaridade, $64 \%$ não possuía renda, $42.3 \%$ tinha $1-2$ filhos e $66.7 \%$ apresentou sintomas de Transtorno Mental Comum (Audi et al., 2016). Além disso, os autores encontraram que $76.3 \%$ das participantes relatou sofrer violência no ano anterior ao encarceramento, sendo $7.1 \%$ psicológica, $31.4 \%$ física e $7.8 \%$ sexual; $41.6 \%$ provinham de lares em que estiveram expostas à violência e $45.1 \%$ relataram ter sofrido abusos infantis antes dos 15 anos (26.9\% físico e $18.2 \%$ sexual). Dessa forma, percebe-se que as características das encarceradas mantém um padrão de alta vulnerabilidade social.

Um dos estudos pioneiros sobre a temática do encarceramento feminino nos Estados Unidos (Greene, Haney \& Hurtado, 2000), foi realizado com 102 mulheres encarceradas e investigou a relação dos fatores de risco vivenciados na infância por mulheres presas e os fatores de riscos aos quais seus filhos estavam expostos. Os resultados apontaram que $86 \%$ das mães e $83 \%$ das crianças sofreram maus-tratos na infância. Os principais tipos de maus-tratos experienciados por esta população foram: assistir a episódios de violência intrafamiliar (60\% dos casos das mães e $69 \%$ das crianças); sofrer abuso fisico ( $65 \%$ das mães e $44 \%$ de seus filhos) e sofrer abuso sexual (com $55 \%$ das mães e $9 \%$ no que diz respeito a seus filhos), evidenciando a relação de intergeracionalidade dos maus-tratos ao longo da infância.

Estudos sobre a população encarcerada na realidade americana (Dalley, 2002), canadense (Elizabeth Fry Society of Greater Vancouver-EFry, 2015) e inglesa (Murray, 2014) evidenciam que a implementação de projetos e políticas públicas para a prevenção dos maus-tratos na infância ou que ajudem a diminuir os danos já instalados apresentam resultados positivos. Tais dados são animadores, principalmente porque o fato de ser filho, mãe ou pai de um encarcerado potencializa a probabilidade de envolvimento em situações de risco (Lee, Fang \& Luo, 2013). 
Considerando o aumento anual da população carcerária feminina no Brasil, a situação precária de nossas cadeias, a falta de planejamento para a ressocialização das encarceradas e a escassa possibilidade de prevenção de ingresso no mundo criminal, este estudo teve por objetivo descrever o perfil de mães encarceradas e identificar os fatores de risco e proteção presentes em seu histórico de vida, de maneira a incentivar políticas públicas para a prevenção da intergeracionalidade carcerária. Justifica-se a relevância e originalidade do estudo, pois não foram encontradas publicações brasileiras a respeito de tais objetivos na revisão realizada pelos autores (ver também Ormeno, Fogo, Santini \& Williams, 2016; Ormeno, Maia \& Williams, 2013; Ormeno \& Stelko-Pereira, 2013).

\section{Método}

Participantes e Local

Participaram do estudo 152 mães encarceradas com filhos de 0-12 anos de idade. Do total, 83 participantes se encontravam encarceradas em uma penitenciária e 69 delas em quatro cadeias, todas localizadas no interior do Estado de São Paulo. Penitenciárias são os centros nos quais as mulheres estão condenadas e cumprem sentenças e as cadeias são centros de encarceramento provisórios nos quais as encarceradas esperam sentenças ou estão sentenciadas aguardando vagas em penitenciárias.

Instrumento

Para a obtenção dos dados foi elaborada uma entrevista semiestruturada pela primeira autora com base no estudo de Cunningham e Baker (2003); no relatório da Organização Mundial de Saúde em parceria com a International Society for the Prevention of Child Abuse and Neglect - ISPCAN (Sociedade Internacional para a Prevenção de Abuso e Negligência contra a Criança- Organização Mundial da Saúde-OMS/ISPCAN, 2006); além de informações resultantes da revisão da literatura científica internacional.

Tal roteiro foi submetido à apreciação de três juízes das áreas de Direito, Direitos Humanos e Psicologia, tendo sido feitas alterações quando pertinentes. A aplicação do roteiro da entrevista tinha duração de 60 minutos, em média. $O$ instrumento final contém os seguintes tópicos: a) Dados pessoais e demográficos da encarcerada: escolaridade; renda; composição familiar; tipo de disciplina utilizada na família de origem; e histórico de violência física, sexual ou psicológica na infância; b) Vida conjugal: a idade na qual ela teve seu primeiro relacionamento sexual; as características dos 
relacionamentos passados e do atual; a idade em que saiu de casa e por qual motivo; histórico de violência por parte de parceiro; idade da primeira gravidez; número de filhos; e qualidade de relacionamento com o parceiro; c) Saúde e drogadição: histórico de problemas de saúde e uso de drogas; d) Cuidados em relação aos filhos: como educavam as crianças; os conhecimentos sobre necessidades, direitos e obrigações das crianças e dos pais; e) Dados relacionados ao crime pelo qual a mulher fora encarcerada, o motivo, o tempo da condenação e situação legal no momento; e f) Rede de apoio social: amigos, locais aos quais poderia solicitar ajuda e fontes de apoio do governo.

\section{Procedimento}

O projeto foi aprovado pelo Comitê de Ética da Universidade Federal de São Carlos (CAAE 0016.0135.000-09, bem como pelo centro nos quais se encontravam as encarceradas (CEP-SAP 023/2009). Participaram do estudo apenas as mães que assinaram o Termo de Consentimento Livre e Esclarecido (TCLE).

Para a triagem das participantes nas cadeias, o primeiro contato com as encarceradas foi realizado no parlatório (local destinado para as detentas receberem seus advogados). De modo a participar do estudo, as pesquisadoras informavam sobre a pesquisa e aquelas que demonstraram interesse eram chamadas ao parlatório, sendo esclarecidas as questões éticas e em seguida era iniciada a entrevista. No caso da penitenciária, as entrevistas ocorreram na sala em que as mesmas realizavam curso de artes. Foi composta uma lista com os nomes das mulheres que tinham filhos de 0-12 anos de idade, segundo informações do setor administrativo das instituições carcerárias. Em seguida, foi feito um sorteio e a mãe encarcerada sorteada era convidada a participar da entrevista, sendo que no caso de a mesma não aceitar, era realizado um novo sorteio.

\section{Análise de dados}

Os dados obtidos foram analisados por meio de um roteiro para sistematização de acordo com os objetivos propostos e avaliados em tabelas do programa Excel, sendo em seguida tabulados em gráficos e tabelas de acordo com Statistical Analysis System. Considerando que os dados foram coletados em cinco instituições diferentes (quatro cadeias e uma penitenciária), foi realizado o teste estatístico Quiquadrado entre as variáveis socioeconômicas. Como não houve diferenças significativas $(p>0.785)$ entre os institutos prisionais, os dados foram analisados como um todo. Os fatores de risco na infância e na vida adulta das participantes com alta porcentagem de ocorrência foram analisados por meio do modelo de regressão 
logística, com um nível de significância de 5\%. Os dados foram interpretados como razão de chances (odds ratio, O.R.), ou seja, representado a possibilidade de um evento ocorrer em uma amostra de participantes.

\section{Resultados}

A seguir será descrito o perfil das mães encarceradas participantes desta pesquisa, categorizado da seguinte maneira: (I) dados sociodemográficos; (II) fatores de proteção e risco vividos na infância; e (III) fatores de risco na vida adulta.

\section{Dados sociodemográficos}

Em um total de 152 participantes, a idade média era de 28.9 anos ( $D P=6.4)$; no que diz respeito ao estado civil, $40.1 \%(n=61)$ eram solteiras; $34.2 \% \quad(n=52)$ viviam em União Estável; $9.9 \% \quad(n=15)$ eram divorciadas; $6.6 \%(n=10)$ casadas e $4.6 \%(n=7)$ separadas e viúvas respectivamente. Com relação à etnia, $51.3 \%$ se declararam pardas; seguidas por brancas com $32.9 \%$; negras $12.5 \%$; $2.6 \%$ amarelas e $0.7 \%$ indígena. Quanto ao número de filhos, este variou de 1 a 11 filhos por participante, com um total de 209 crianças ( 114 meninos e 95 meninas), com média de 3.03 filhos por participante $(\mathrm{DP}=1.67)$. Acerca da escolaridade, $60 \%$ tinham cursado apenas até 4 a série do ensino fundamental; $20.4 \%$ frequentou o ensino médio; $1.3 \%$ era analfabeta; $1.3 \%$ possuía nível superior e $0.7 \%$ estudara na APAE. A renda mensal variou entre $R \$ 20,00$ a $R \$ 10.000,00$, sendo que quase metade das mulheres $(48.5 \%)$ vivia com uma renda de até um salário mínimo; a outra metade $(46.7 \%)$ não possuía renda; e apenas $4.8 \%$ das participantes recebia mais de dois salários mínimos (relatado como fruto de atividades ilícitas). O salário mínimo correspondia a $\mathrm{R} \$ 465,00$ na época da coleta de dados. Adicionalmente, $29.4 \%$ das mães trabalhavam com carteira assinada. Com relação à situação carcerária, $61.84 \%$ das mulheres estavam sentenciadas; $31.58 \%$ tinham uma sentença provisória; $3.94 \%$ estavam em regime semiaberto e $1.32 \%$ não soube informar sua situação judicial. No que diz respeito ao crime pelo qual estavam encarceradas, $48.7 \%$ foram presas por tráfico de drogas; $14.52 \%$ por crimes considerados hediondos; $13.82 \%$ por roubo e $6.6 \%$ por furto. Além disso, $15.54 \%$ das mães foram enquadradas em mais de um artigo, ou seja, cometeram mais de um tipo de delito. A respeito da assistência judicial, $53.95 \%$ das mães relataram ter utilizado a Defensoria Pública e $38.82 \%$ foram assistidas por um advogado particular. O tempo decorrido desde que foram encarceradas apresentou uma média de 22.6 meses, uma mediana de 16 meses e 
$\mathrm{DP}=23.07$. O tempo que faltava para cumprir a pena correspondeu em 39.06 meses em média, sendo a mediana igual a 15 meses e 0 $\mathrm{DP}=48.25$ meses.

Fatores de proteção e risco vividos na infância

A Figura 1 apresenta os principais fatores de risco vivenciados na infância e na vida adulta das participantes. Foi possível identificar apenas um fator de proteção relatado pelas participantes: o suporte emocional de um cuidador. Ao serem questionadas se alguém as fazia se sentir especial na infância, $86.84 \%$ das mães encarceradas respondeu positivamente. Em $75.24 \%$ dos casos, as participantes indicaram tal pessoa como sendo alguém da família, sendo que $24.43 \%$ indicou ser a respectiva mãe. Cabe mencionar que $11.94 \%$ das participantes relataram não possuir qualquer pessoa que as faziam se sentir especial, e duas participantes não responderam à pergunta.

a) Exposição à Violência Conjugal entre os Genitores: das 152 participantes, 70 delas ou $(46.05 \%)$ relataram que foram expostas à violência conjugal do pai contra a mãe, sendo que a violência considerada leve (dar empurrões e tapas) ocorreu muito frequentemente com $18.57 \%$ das participantes. A violência analisada como moderada (dar socos ou arremessar algum objeto com força) ocorreu muito frequentemente com $17.14 \%$ das mães e, no que diz respeito à violência grave (ameaçar com faca ou arma, com intenção de ferir a genitora), $11.43 \%$ respondeu que isto acontecia muito frequentemente. A exposição à violência física da mãe contra o pai ocorreu para $23.03 \%$ das participantes, sendo que $40 \%$ estiveram expostas algumas vezes à violência leve, $28.57 \%$ à violência moderada e $14.29 \%$ à violência grave de maneira frequente.

b) Outros tipos de maus-tratos: Ao se questionar qual era a forma de disciplina que os pais utilizavam, dois terços ou $67.11 \%$ das participantes descreveram que era utilizada a punição corporal. No que diz respeito à violência psicológica, $28.29 \%$ apontaram que alguém da família as chamava de nomes degradantes, sendo que a negligência do cuidador foi experienciada por $15.13 \%$ das participantes. Com relação ao abuso sexual, $24(15.78 \%)$ das participantes declararam ter sofrido tal abuso na infância. O ofensor sexual era uma pessoa conhecida da vítima (14 ou 9.22\%), sendo que para oito participantes os ofensores eram parentes. Dentre as 24 participantes, apenas 10 tiveram o abuso sexual notificado; as demais apontaram os seguintes motivos pela ausência de notificação: pessoas próximas não acreditarem no abuso revelado, sentir medo e ou sofrer ameaças. Adicionalmente, cinco participantes não identificaram um histórico de vitimização sexual, mas, ao responderem as demais perguntas, tal fenômeno foi caracterizado 
(por exemplo, relataram que sua primeira experiência sexual ocorreu aos doze anos de idade com parceiro de 27 anos de idade).

c) Prisão de Familiares: a separação de seus cuidadores ainda na infância ocorreu com $9.87 \%$ das participantes, sendo que em $4.62 \%$ dos casos o pai estava encarcerado. Os crimes cometidos por eles foram classificados como hediondos e a pena cumprida variou de sete a 20 anos. As participantes da pesquisa tinham entre 0-7 anos quando ocorreu a prisão de seus pais.

Fatores de risco na vida adulta

a) Violência pelo Parceiro Íntimo: Segundo as participantes, $63.82 \%$ delas foram agredidas fisicamente por seu companheiro; em $15.13 \%$ dos casos tal violência foi avaliada como moderada e em $8.55 \%$ como grave. Além de violência física, $46.05 \%$ das participantes relataram ter sofrido violência psicológica pelo companheiro.

b) Prisão de Familiares: $68.42 \%$ das mães participantes afirmaram ter familiares presos em sua vida adulta, sendo que $46 \%$ desses eram parentes de 1 o grau e $4.61 \%$ deles eram os cônjuges. Antes de serem encarceradas, $35.13 \%$ das mulheres havia visitado uma instituição prisional, sendo que em $28.95 \%$ dos casos as visitas tinham o objetivo de visitar o companheiro; $13.16 \%$ visitar a irmã/o; $9.21 \%$ eram reincidentes e $7.89 \%$ visitaram outros parentes.

c) Tentativas de Suicídio: $36.18 \%$ das participantes relataram ter realizado tentativas de suicídio. Dessas, $15.13 \%$ realizaram duas tentativas; $11.18 \%$ uma única tentativa e $3.29 \%$ mais de três tentativas de suicídio.

d) Uso/abuso de Álcool, Cigarro e Drogas Ilícitas: Um dos problemas enfrentados pelas mulheres foi o consumo uso/abuso de substâncias lícitas e não lícitas. As participantes foram solicitadas a pontuar em uma escala Likert de 1 a10 o consumo de drogas, cigarros e bebida alcoólica. Acerca do uso de drogas ilícitas, tais como maconha e cocaína, $30.26 \%$ afirmou ser usuária e $17.76 \%$ relatou tal uso como frequente. Dentre as drogas lícitas, $36.24 \%$ das participantes relatou fazer uso de bebida alcoólica e $64.47 \%$ das mulheres eram tabagistas, sendo que $38.82 \%$ destas afirmaram fazer uso elevado e frequente do cigarro.

Três variáveis associadas a fatores de risco na infância e na vida adulta apresentaram alta porcentagem de ocorrência na vida das participantes, sendo assim analisadas por meio do modelo de regressão logística, com um nível de significância de 5\%. São elas: (a) Violência pelo Parceiro Íntimo (VPI); (b) Prisão de Familiares; e (c) Tentativa de Suicídio. Os dados encontram-se ilustrados na Tabela 1. 
Violência pelo Parceiro Íntimo

Observou-se que as participantes vítimas de VPI apresentavam maior chance de tentar suicídio (4.3); maior probabilidade de ter tido experiência sexual antes dos 18 anos com alguém com mais de 5 anos de diferença (5.6); maior chance de ter um familiar preso (4) e maior chance de estar trabalhando antes do encarceramento (3.8).

Prisão de Familiares

Analisando-se o cruzamento entre as variáveis "violência pelo parceiro íntimo" e "prisão de familiares quando adulta", notou-se que a porcentagem das mulheres agredida pelo parceiro é maior em mulheres que tiveram familiares presos quando adultas. Pelo teste do Qui-quadrado, verificou-se uma relação significativa entre as variáveis: a participante ter sofrido negligência na infância $(p=0.0110)$, motivo por ter visitado presídio $(p=0.0001)$; e violência pelo parceiro íntimo $(p=0.0389)$. Houve uma diferença significativa entre as mulheres que já tiveram familiares presos quando adultas em relação a um histórico de negligência: adicionalmente houve uma maior porcentagem de mulheres com histórico de negligência que já teve familiares presos $(n=104,68.4 \%)$ do que as mulheres que não tiveram familiares presos. 
Tabela 1

Análise de regressão logística entre as variáveis estudadas $(N=95)$

\begin{tabular}{|c|c|c|c|c|c|c|}
\hline Parâmetro & Resposta & Estimativa & $\begin{array}{c}\text { Estatística } \\
\text { de Wald }\end{array}$ & P-valor & O.R. & I.C. $95 \%$ \\
\hline \multicolumn{7}{|l|}{$\begin{array}{l}\text { Violência Íntima } \\
\text { pelo Parceiro }\end{array}$} \\
\hline Intercepto & & -2.6217 & 6.3844 & $0.0115^{*}$ & --- & $\cdots$ \\
\hline \multirow{2}{*}{$\begin{array}{l}\text { Tentativa de } \\
\text { suicídio }\end{array}$} & Sim & 1.4701 & 6.0851 & $0.0136^{*}$ & 4.350 & $\begin{array}{c}1.353 \\
13.988\end{array}$ \\
\hline & Não & -- & -- & $--\cdot$ & 1.00 & 1.00 \\
\hline \multirow[t]{2}{*}{$\begin{array}{l}\text { Relação sexual } \\
\text { antes dos } 18 \text { anos } \\
\text { com parceiro } 5 \\
\text { anos mais velho }\end{array}$} & Sim & 1.7301 & 8.4241 & $0.0037^{*}$ & 5.641 & $\begin{array}{c}1.754 \\
18.146\end{array}$ \\
\hline & Não & $\cdots$ & -- & --- & 1.00 & 1.00 \\
\hline \multirow[t]{2}{*}{$\begin{array}{l}\text { Prisão de familiares } \\
\text { quando adulta }\end{array}$} & Sim & 1.3942 & 5.7318 & $0.0167^{*}$ & 4.032 & $\begin{array}{c}1.288 \\
12.624\end{array}$ \\
\hline & Não & -- & -- & -- & 1.00 & 1.00 \\
\hline \multirow[t]{2}{*}{$\begin{array}{l}\text { Trabalhar antes do } \\
\text { encarceramento }\end{array}$} & $\operatorname{sim}$ & 1.3426 & 6.0676 & $0.0138^{*}$ & 3.829 & $\begin{array}{c}1.316 \\
11.144\end{array}$ \\
\hline & Não & --- & $\cdots$ & --- & 1.00 & 1.00 \\
\hline \multicolumn{7}{|l|}{ Prisão de familiares } \\
\hline Intercepto & & -0.2485 & 0.4627 & 0.4964 & $\cdots$ & $--\cdot$ \\
\hline \multirow{2}{*}{$\begin{array}{l}\text { Ter sofrido abuso } \\
\text { sexual }\end{array}$} & Sim & 1.4233 & 3.1460 & $0.0761 * *$ & 4.151 & $\begin{array}{c}0.861 \\
20.006\end{array}$ \\
\hline & Não & -- & --- & --- & 1.00 & 1.00 \\
\hline \multirow{2}{*}{$\begin{array}{l}\text { Visita à instituição } \\
\text { prisional }\end{array}$} & Sim & 1.3231 & 7.5263 & $0.0061^{*}$ & 3.755 & $\begin{array}{l}1.459 \\
9.663\end{array}$ \\
\hline & Não & $\cdots$ & $\cdots$ & --- & 1.00 & 1.00 \\
\hline \multicolumn{7}{|l|}{$\begin{array}{l}\text { Tentativa de } \\
\text { suicídio }\end{array}$} \\
\hline Intercepto & & 2.4196 & 0.9476 & 0.3303 & $\cdots$ & $--\cdot$ \\
\hline $\begin{array}{l}\text { Idade da } 1^{a} \text { relação } \\
\text { sexual }\end{array}$ & & -0.3732 & 4.5588 & $0.0327^{*}$ & 0.689 & $\begin{array}{l}0.489 \\
0.970\end{array}$ \\
\hline \multirow{2}{*}{$\begin{array}{l}\text { Denúncia do abuso } \\
\text { sexual }\end{array}$} & Sim & 2.7745 & 4.6386 & $0.0313^{*}$ & 16.031 & $\begin{array}{c}1.284 \\
20.217\end{array}$ \\
\hline & Não & $\cdots$ & $\cdots$ & $-\cdots$ & 1.00 & 1.00 \\
\hline \multirow{2}{*}{$\begin{array}{l}\text { Violência } \\
\text { psicológica }\end{array}$} & Sim & 1.5204 & 6.3666 & $0.0116^{*}$ & 4.574 & $\begin{array}{c}1.404 \\
14.901\end{array}$ \\
\hline & Não & --- & --- & --- & 1.00 & 1.00 \\
\hline \multirow{2}{*}{$\begin{array}{l}\text { Violência pelo } \\
\text { parceiro íntimo }\end{array}$} & Sim & 1.6930 & 6.0810 & $0.0137^{*}$ & 5.436 & $\begin{array}{c}1.415 \\
20.875\end{array}$ \\
\hline & Não & $\cdots$ & $\cdots$ & $\cdots$ & 1.00 & 1.00 \\
\hline
\end{tabular}

Apenas as variáveis "ter sofrido abuso sexual antes da prisão" e "ter visitado um presídio, cadeia ou instituição penal" foram significativas para predizer se a mulher teve familiares presos quando adulta. Vale ressaltar que apenas a variável "ter visitado um presídio" foi significativa ao nível de $5 \%$ de significância ( $p$-valor $<0.05)$ e a variável "ter sofrido abuso sexual antes da prisão" foi significativa apenas considerando-se $10 \%$ de p-valor. As razões de chances obtidas por este modelo mostram que mulheres que tiverem familiares presos quando adultas apresentaram maiores chances de terem sido abusadas sexualmente (4.151) e de terem visitado um presídio, cadeia ou instituição penal antes de seu próprio encarceramento (3.755). 
Tentativa de Suicídio

Em relação a relatos de tentativas de suicídio, os testes Qui-quadrado foram significativos para: etnia $(p=0.0135)$; ter sido vítima de abuso sexual na infância $(p=0.0001)$; e ter sido separada dos pais/cuidadores quando criança pelo fato de estarem presos $(p=0.0456)$. Identificou-se maior porcentagem entre afrodescendentes que já tentaram o suicídio. Dentre as mulheres que relataram histórico de abuso sexual, identificou-se uma porcentagem maior em relação às que já tentaram suicídio em comparação às que não tentaram. O mesmo aconteceu quando a participante esteve separada dos pais/cuidadores quando criança pelo fato de esses estarem presos, com maior porcentagem de ocorrência nas mulheres que já tentaram suicídio (33\%). Os dados apresentados na Tabela 1 indicam maior chance para tentativas de suicídio nos casos em que as mulheres relataram: iniciação sexual precoce $(0.6)$; notificação de abuso sexual (16.03); histórico de violência psicológica na infância por membros da família (4.57); e histórico de violência pelo parceiro íntimo (5.43).

\section{Discussão}

Com relação às principais características das 152 mães encarceradas, observou-se no presente estudo que em geral a mãe encarcerada é jovem; solteira (apenas $6.6 \%$ era casada); possuindo em média três filhos; de etnia afrodescendente (pardas e negras); apresentando baixa renda e escolaridade e estava geralmente encarcerada pelo crime de tráfico de drogas. Tal perfil é condizente com o perfil de mulheres encarceradas descrito pela literatura nacional (Audi et al., 2016; Canazaro \& Argimon, 2010; Falbo, Souza, Benício, Piscoya, Linhares \& Vidal, 2004; Lima et al., 2013) e pela literatura internacional (Almeda, 2003; Craig, 2009; Dalley, 2002; Greene et al., 2000).

Os dados observados aqui com relação ao crime mais frequentemente cometido pelas mulheres também corroboram com estudos nacionais (Canazaro \& Argimon, 2010; Dell Agnolo et al., 2013) e internacionais (Almeda, 2003; Craig, 2009), apontando o tráfico de drogas como sendo um dos principais motivos pelo encarceramento mundial, principalmente na população feminina. Considerando que a maioria das mulheres encarceradas é mãe e que, ao serem encarceradas deixam seus filhos expostos muitas vezes às mesmas situações de vulnerabilidade vividas por elas, argumenta-se que o encarceramento de mães nos moldes atuais gera uma vulnerabilidade para os filhos. Quando se discute a manutenção das relações familiares, vê-se que a violência praticada contra a mulher presa 
ultrapassa os limites da pena, atingindo também a sua família e, especialmente, os filhos nascidos nas unidades prisionais. Um dos aspectos negativos mais incidentes nas vidas das mulheres presas é o distanciamento da família, diferentemente da realidade vivenciada pelos homens presos, os quais, em geral, mantêm seus vínculos familiares durante o período de encarceramento (CEJIL, 2007).

O segundo crime mais frequente pelo qual as participantes foram encarceradas (roubo) necessita de uma análise cautelosa, pois, no discurso das participantes, esse parece estar relacionado ao uso de drogas, isto é, elas roubaram para poder sustentar a adição, sendo tal contexto taém observado no estudo de Lopes, de Mello e Argimon (2010). Portanto, tal ato deve ser encarado como crime, mas também como um problema sério de saúde pública. Além disso, Mauá e Baltieri (2012) apontam que o ato de roubar por mulheres encarceradas estaria relacionado a histórico carcerário de familiares, fazendo com que tais mulheres se engajassem em comportamentos criminais precocemente, e o uso de drogas estaria relacionado significativamente a tais atos criminais.

O presente estudo identificou diversos fatores de risco aos quais as mulheres encarceradas experienciaram ao longo da vida. Durante a infância, observou-se a exposição à violência conjugal dos pais (uma modalidade de violência psicológica) e outras modalidades de maustratos, sendo a punição corporal a mais frequente; bem como a prisão de algum familiar. $\mathrm{Na}$ idade adulta, a maioria das participantes era vítima de violência pelo parceiro; possuía familiares encarcerados; fazia uso abusivo de álcool, tabaco e drogas; e havia feito tentativa de suicídio.

Em contraste, observou-se apenas um fator de proteção na infância de tais mulheres: um cuidador que valorizou positivamente a autoestima da participante, fazendo com que ela se sentisse especial. Questiona-se se tal percepção positiva, geralmente da figura da genitora, seria fruto das expectativas geradas por sugestão social da entrevista. Desse modo, a escassez de fatores de proteção e excesso de fatores de risco constituem um contexto de intensa vulnerabilidade que contribuem para tais mulheres ingressarem numa trajetória criminal, caminho esse com poucas perspectivas positivas de uma vida digna e sem violência.

Adicionalmente, verificou-se que diversos fatores de risco presentes na vida das mulheres encarceradas estavam associados significativamente a ser vítima de violência pelo parceiro íntimo, como histórico de tentativa de suicídio, abuso sexual, ter familiares encarcerados e o desemprego. Tais variáveis também foram observadas na literatura com a mesma população (Lima et al., 2013; Organização Mundial da Saúde - OMS, 2012). Cabe ressaltar, entretanto, que as participantes indicaram dificuldades na compreensão do fenômeno da violência contra a mulher, pois em 
vários relatos as mães encarceradas banalizaram a violência sofrida: "um tapa de vez em quando, como em todo casal". Sendo assim, tais dados podem estar subestimados e a violência contra a mulher pode ser mais expressiva do que a relatada nesse estudo.

Outros fatores de risco presentes na vida das participantes foram associados significativamente a ter um histórico de prisão de familiares na infância, como a negligência, o abuso sexual e a violência pelo parceiro íntimo na vida adulta. Tais dados ressaltam a importância dos cuidados maternos e paternos para o desenvolvimento saudável da criança, bem como o impacto que o encarceramento de um familiar pode acarretar (Ferrari, 2010).

Por fim, foram identificados vários fatores de risco das mães encarceradas, participantes da pesquisa, associados significativamente com tentativas de suicídio, tais como: etnia afrodescendente; separação dos pais/cuidadores na infância por estar presos; violência psicológica na infância; e violência pelo parceiro íntimo. Além disso, outros dados significativos chamam à atenção: a) mulheres que notificaram o abuso sexual apresentaram 16 vezes mais chances de tentar o suicídio em comparação às que não notificaram. Tal dado, ao contrário de sugerir que a notificação do abuso sexual está associada a tentativas de suicídio, está provavelmente relacionado ao fato de que os casos mais graves de abuso sexual foram notificados e os mais leves não, reforçando a associação forte apontada pela literatura entre histórico de abuso sexual e ideação ou tentativa de suicídio (Williams, 2014). Por outro lado, uma segunda hipótese (que não invalida a anterior) seria que a alta taxa de suicídios associadas à notificação estaria relacionada a problemas resultantes da prisão de um pai ofensor sexual e os desdobramentos difíceis que isso acarreta para toda a família (Finkelhor, Ormrod \& Turner, 2009).

A taxa de tentativa de suicídio encontrada neste estudo é considerada alta $(36.18 \%)$ se comparada à população geral. Por exemplo, Botega et al. (2009) encontraram uma taxa de $2.8 \%$ na população de Campinas. No entanto, ao ser comparado com a taxa de tentativa de suicídio da população de encarcerados, tal dado não é discrepante. O estudo de Sharma (2009), realizado na Austrália, informa que o número de tentativas de suicídios em encarcerados ao ingressar nos centros prisionais é maior quando o encarcerado é sentenciado, devido ao desespero e crença que a vida está acabada. No estudo com mulheres encarceradas do Rio Grande do Sul (Canazaro \& Argimon, 2010), $13.6 \%$ das participantes tinham história pregressa de tentativas de suicídio e $4.2 \%$ apresentaram tal tentativa de suicídio durante o aprisionamento.

No que diz respeito à intergeracionalidade da violência intrafamiliar entre as mães encarceradas, foi observada tal incidência nas duas gerações. Esse dado é corroborado pelo estudo de Falbo et al. (2004), 
em que o histórico de maus-tratos por parte dos pais ou cuidadores contribuiu para o risco de que as participantes fossem autoras de agressões contra seus filhos e se envolvessem em atividades criminais. Além disso, crianças e adolescentes expostos a situações de vulnerabilidade precocemente podem apresentar prejuízos no desenvolvimento cerebral de modo a causar déficits cognitivos, como a dificuldade na aprendizagem (Oliveira, Scivoletto \& Cunha, 2010; Ormeno \& Stelko-Pereira, 2015). Sendo assim, destaca-se a necessidade urgente de políticas públicas de atenção às mães encarceradas e seus filhos, visando à ruptura da intergeracionalidade da violência intrafamiliar (Dalley, 2002; Santini, D'Affonseca, Ormeño, \& Williams, 2012).

Diversos estudos apontam uma relação existente entre ser vítima de maus-tratos na infância e vivenciar um relacionamento violento com o(a) parceiro(a) na vida adulta (Durrant \& Ensom, 2012; Widom, Czaja \& Dutton, 2014), principalmente porque a criança nessa situação de violência dificilmente aprende habilidades adequadas de resolução de problemas sociais, recorrendo a um padrão de passividade e aceitação da violência imposta por outras pessoas; ou, por outro lado, a um padrão agressivo para enfrentar conflitos (Cecconello, De Antoni \& Koller, 2003; Santini et al., 2012; Widom et al., 2014). Nesse sentido, o indivíduo adulto com histórico de maustratos na infância pode se envolver em situações de risco com maior frequência, como, por exemplo, relacionamentos amorosos violentos e atos que infrinjam a lei, em comparação ao que não teve tal histórico (Lamers-Winkelman, Willemen \& Visser, 2012; Santini et al., 2012; Widom et al., 2014).

\section{Conclusão}

A mãe encarcerada do presente estudo apresentou o mesmo perfil das mulheres encarceradas em geral no mundo, marcada por situações de risco e vulnerabilidade social. Considerando que essas mulheres são mães, jovens, com baixa escolaridade, esses fatores apontam a necessidade de um maior investimento do poder público em políticas de atenção às mulheres encarceradas e seus filhos, bem como nos setores de educação, projetos de planificação familiar, inserção de jovens no mercado de trabalho e prevenção da violência intrafamiliar, visando uma quebra da intergeracionalidade de vulnerabilidade social vivenciados pelas participantes e consequentemente por seus filhos.

Seria possível pensar em alternativas menos restritas em termos da liberdade do indivíduo, como, por exemplo, a justiça restaurativa. Não se trata de não penalizar o erro, mas sim de pensar que a solução pode estar sendo mais onerosa (considerando os custos de 
uma pessoa encarcerada para os cofres públicos e o dano que o encarceramento da mãe faz à criança), o que também gera outros problemas associados, como por exemplo, a busca por novos cuidadores para as crianças. Cabe lembrar que, em geral, quando o pai é encarcerado, a mãe é quem fica responsável com o cuidado dos filhos; no entanto, quando a mãe é encarcerada, os mesmos ficam sobre cuidados dos familiares maternos (Gabel \& Johnston, 1995; Ormeno, Maia \& Williams, 2013; Stella, 2009).

No Brasil, há pouco investimento no setor penitenciário para o que seria essencial, como a estrutura física e espaço adequados, condições dignas de ocupar o detento de forma à ressocialização, etc. Historicamente, no país o que se prioriza é remediar/consertar em vez de prevenir. Ressaltamos aqui a necessidade urgente de prevenção especialmente dos fatores de risco que levam os indivíduos a chegar ao encarceramento. Nesse sentido, em consonância com o que é desenvolvido em outros países, como o Canadá, por exemplo, há ações em presídios com resultados positivos, percebendo-se que existe investimento, tanto no tratamento dos indivíduos presos, como na prevenção dos problemas associados ao encarceramento, como os apontados nesse estudo: lares monoparentais chefiados por mulheres em situação de baixa renda e baixa escolaridade, a existência da violência contra a mulher de modo grave e frequente, a alta prevalência de maus-tratos contra a criança em suas diversas formas, o envolvimento com drogas como forma de enfrentamento para tais estressores e a visibilidade do ingresso no tráfico de drogas como meio para conseguir renda e sustentar sua família (CEJIL, 2007; Dell Agnolo et al., 2013). Além disso, observouse a necessidade de se desenvolver ações relacionadas aos cuidados da saúde mental da população feminina no processo e após o encarceramento, dada a alta ocorrência de tentativas de suicídio entre as mães detentas.

O presente estudo reforça a necessidade premente de ações sistemáticas de prevenção da intergeracionalidade carcerária, bem como ações de reestruturação e adaptação dos presídios para a realidade feminina, colaborando para a reinserção dessas mulheres na sociedade. Finalmente, o estudo descortina um fator de risco adicional associado à etnia da mãe afrodescendente encarcerada (maior probabilidade de tentativa de suicídio), o que requer políticas públicas preventivas de apoio em saúde mental, suporte à maternagem dos filhos, bem como programas preventivos às crianças. 


\section{Referências}

Almeda, E. (2003). Mujeres encarceladas. Barcelona: Editorial Ariel.

Audi, C., Santiago, S., Andrade, M., \& Francisco, P. (2016). Inquérito sobre condições de saúde de mulheres encarceradas. Saúde Debate, 40(109), 112-124. doi: 10.1590/0103-1104201610909

Botega, N. J., Marín-León, L., Oliveira, H. B. de, Barros, M. B. de A., Silva, V. F. da, \& Dalgalarrondo, P. (2009). Prevalências de ideação, plano e tentativa de suicídio: um inquérito de base populacional em Campinas, São Paulo, Brasil. Cadernos de Saúde Pública, 25(12), 2632-2638. doi:10.1590/S0102311X2009001200010

Canazaro, D., \& Argimon, I. I. de L. (2010). Características, sintomas depressivos e fatores associados em mulheres encarceradas no Estado do Rio Grande do Sul, Brasil. Cadernos de Saúde Pública, 26(7), 1323-1333. doi: 10.1590/S0102-311X2010000700011

Cecconello, A. M., De Antoni, C., \& Koller, S. H. (2003). Praticas educativas, estilos parentais e abuso fisico no contexto familiar. Psicologia em Estudo, 8 (especial), 45-54. doi: 10.1590/S141373722003000300007

Centro pela Justiça e pelo Direito Internacional-CEJIL. (2007). Relatório sobre mulheres encarceradas no Brasil. Retrieved from http: //carceraria.org.br/wpcontent/uploads/2013/02/Relato\% CC\% 81rio-para-OEA-sobreMulheres-Encarceradas-no-Brasil-2007.pdf

Craig, S. C. (2009). A Historical Review of Mother and Child Programs for Incarcerated Women. The Prison Journal, 89(1 Suppl), 35S53S. doi: 10.1177/0032885508329768

Cunningham, A., \& Baker, L. (2003). Waiting for Mommy: Giving a Voice to the Hidden Victims of Imprisonment. London, Canada: Center for Children and Families in The J ustice System.

Dell Agnolo, C. M., Belentani, L., Jardim, A., Carvalho, M., \& Pelloso, S. (2013). Perfil de mulheres privadas de liberdade no interior do Paraná. Revista Bahiana de Saúde Pública, 37(4), 820-834.

Diuana, V., Ventura, M., Simas, L., Larouzé, B., \& Correa, M. (2016). Direitos reprodutivos das mulheres no sistema penitenciário: Tensões e desafios na transformação da realidade. Ciência \& Saúde Coletiva, 21(7), 2041-2050. doi:10.1590/141381232015217.21632015

Dalley, L. P. (2002). Policy implications relating to inmate mothers and their children: Will the Past be Prologue? The Prison J ournal, 82(2), 234-268. doi: 10.1177/003288550208200205

Durrant, J. \& Ensom, R. (2012). Physical punishment of children: Lessons from 20 years of research. Canadian Medical Association Journal, 184, 1373-1377. 
Elizabeth Fry Society of Greater Vancouver-EFry. (2015). EFry's 2015 Annual Report. Acessado em: http://www. elizabethfry.com/publications/docs/Efry-AnnualReport-2015.pdf

Falbo, G. H., Souza, A. I. de, Benício, L., Piscoya, M. D., Linhares, R. S. \& Vidal, S. A. (2004). Manual de orientação para profissionais de saúde no atendimento à criança e ao adolescente vítimas de violência. Recife: Gráfica e Editora Liceu.

Ferrari, I. F. (2010). Mulheres encarceradas: Elas, seus filhos e nossas políticas. Revista Mal Estar e Subjetividade, 10(4), 1325- 1354.

Ferreira, V., Silva, M., Noronha Neto, C., Falbo Neto, G., Chaves, C., \& Bello, R. (2014). Prevalência e fatores associados à violência sofrida em mulheres encarceradas por tráfico de drogas no Estado de Pernambuco, Brasil: um estudo transversal. Ciência \& Saúde Coletiva, 19(7), 2255-2264. doi:10.1590/141381232014197.10012013

Finkelhor, D., Ormrod, R. K., \& Turner, H. A. (2009). The developmental epidemiology of childhood victimization. Journal of Interpersonal Violence, 24(5), 711-31. doi: $10.1177 / 0886260508317185$

Gabel, K., \& Johnston, D. (1995). Children of incarcerated parents. Lexington Books.

Greene, S., Haney, C., \& Hurtado, A. (2000). Cycles of pain: Risk factors in the lives of incarcerated mothers and their children. The Prison Journal, 80(1), 323. doi: $10.1177 / 0032885500080001001$

Infopen Mulheres. (2014). Levantamento de informações penitenciárias. Distrito Federal: Departamento Penitenciário Nacional - Ministério da Justiça.

International Centre for Prison Studies. (2013). World Prision Brief. Acessado em: http://www. prisonstudies.org

Lamers-Winkelman, F., Willemen, A. M., \& Visser, M. (2012). Adverse Childhood Experiences of referred children exposed to Intimate Partner Violence: Consequences for their wellbeing. Child Abuse and Neglect, 36(2), 166-179. doi: $10.1016 /$ j.chiabu.2011.07.006

Lee, R. D.; Fang, X.; Luo, F. (2013). The impact of parental incarceration on the physical and mental health of young adults. Pediatrics Official J ournal of the American Academy of Pediatrics, 131(4), 1188-1195. doi: 10.1542/peds.2012-0627

Lima, G. M. B. de, Pereira Neto, A. de F., Amarante, P. D. de C., Dias, M. D., \& Ferreira Filha, M. de O. (2013). Mulheres no cárcere: Significados e práticas cotidianas de enfrentamento com ênfase 
na resiliência. Saúde Em Debate, 37(98), 446-456. doi: 10.1590/S0103-11042013000300008

Lopes, R. M. F., Melo, D. C. de, \& Argimon, I. I. de L. (2010). Mulheres encarceradas e fatores associados a drogas e crimes. Ciências e Cognição, 15(2), 121-131. Acessado em: http: // www. cienciasecognicao.org/revista/index. php/cec/article /view/308

Maia, J. M. D., \& Williams, L. C. de A. (2005). Fatores de risco e fatores de proteção ao desenvolvimento infantil: Uma revisão da área. Temas Em Psicologia, 13(2), 91-103.

Mauá, F. H. N., \& Baltieri, D. A. (2012). Criminal career-related factors among female robbers in the State of São Paulo, Brazil, and a presumed "revolving-door" situation. Revista Brasileira de Psiquiatria, 34(2), 176-84. doi: 10.1590/S151644462012000200010

Murray, J., Bikleveld, C. C., Farrington, D. P., \& Loeber, R. (2014). Effects of parental incarceration on children: Cross-national comparative studies. Washington, DC: American Psychological Association.

Oliveira, P. A., Scivoletto, S., \& Cunha, P. J. (2010). Estudos neuropsicológicos e de neuroimagem associados ao estresse emocional na infância e adolescência. Revista de Psiquiatria Clinica, 37(6), 270-279. doi: 10.1590/S010160832010000600004

Organização Mundial da Saúde-OMS. (2012). Violence against women by intimate partners: Factors that protect women or put them at risk. Acessado em: http://www.who.int/gender/violence/who_multicountry_study/s ummary_report/chapter2/en/index3.html

Organização Mundial da Saúde-OMS/ISPCAN. (2006). Preventing child maltreatment: a guide to taking action and generating evidence. Acessado em: http: //apps. who.int/ iris/ bitstream/10665/43499/1/9241594365 _eng.pdf

Ormen̄o, G. R., Fogo, J. C., Santini, P. M. \& Williams, L. C. A. (2016). Children of incarcerated women in Brazil: Vulnerability and traumatic experiences in their lives. Journal of Latino/Latin American Studies, 8(2), 10-17. doi: 10.18085/1549-95028.2.10

Ormeno, G. R. \& Stelko-Pereira, A. C. (2013). Mulheres encarceradas: nível de escolaridade e motivos para terem evadido da escola. Revista Faz Ciência, 15, 52-63.

Ormeno, G. R., Maia, J. M. D., \& Williams, L. C. A. (2013). Crianças com pais ou mães encarcerados: Uma revisão da literatura. Revista de Psicologia da Criança e do Adolescente, 4(2), 141- 
161.

Acessado

em:

http: // revistas. lis.ulusiada. pt/index. php/rpca/article/view/426

Quitete, B., Paulino, B., Hauck, F., Aguiar-Nemer, A., \& Silva-Fonseca, V. (2012). Transtorno de estresse pós-traumático e uso de drogas ilícitas em mulheres encarceradas no Rio de Janeiro. Revista Psiquiatria Clínica, 39(2), 43-7. doi:10.1590/S010160832012000200001

Santini, P. M., D'Affonseca, S. M., Ormeño, G. R., \& Williams, L. C. A. (2012). Violência doméstica e encarceramento: Um estudo de caso. Multiciência, (11), 212-222.

Sharma, B. R. (2009). Is attempted suicide an offense? Aggression and Violent Behavior, 14(2), 139-145. doi: 10.1016/j.avb.2009.01.003

Stella, C. (2009). Filhos de mulheres presas: o papel materno na socialização dos indivíduos. Estudos e Pesquisas em Psicologia, 9(2), 292-306.

Widom, C. S., Czaja, S., \& Dutton, M. A. (2014). Child abuse and neglect and Intimate Partner Violence victimization and perpetration: A prospective investigation. Child Abuse \& Neglect, 38(4), 650-663. doi: 10.1016/j.chiabu.2013.11.004

Williams, L. C. A. (2014). Virginia Woolf's history of sexual victimization: A case study in light of current research. Psychology, 05(10), 1151-1164. doi: $10.4236 /$ psych. 2014.510128

Zavaschi, M. L. S. (2009). Crianças e adolescentes vulneráveis. Porto Alegre: Artmed.

\section{Endereço para correspondência}

Gabriela Reyes Ormeno

Universidade Federal do Paraná - UFPR

Rua XV de Novembro, 1299, Centro, CEP 80060-000, Curitiba - PR, Brasil Endereço eletrônico: gabrielareyes@ufpr.br

Paolla Magioni Santini

Pontifícia Universidade Católica de Minas Gerais - PUC-MG

Av. Pe. Cletus Francis Cox, 1661, Jardim Country Club, CEP 37701-355, Poços de Caldas - MG, Brasil

Endereço eletrônico: paollams@gmail.com

\section{Lúcia Cavalcanti de Albuquerque Williams}

Universidade Federal de São Carlos - UFSCar

Rodovia Washington Luís, Km 235, CEP 13565-905, São Carlos - SP, Brasil

Endereço eletrônico: lucia.williams@pq.cnpq.br

Recebido em: 11/04/2015

Reformulado em: 23/10/2016

Aceito em: 20/11/2016 
Gabriela Reyes Ormeno, Paolla Magioni Santini, Lúcia Cavalcanti de Albuquerque Williams

\section{Notas}

* Professora do Departamento de Educação da Universidade Federal do Paraná.

** Professora do Departamento de Psicologia da PUC-MG.

*** Professora Titular do Programa de Pós-Graduação em Psicologia da UFSCar. 